\title{
New features of version 3 of the HYDRUS (2D/3D) computer software package
}

\author{
Jiř́ Šimůnek ${ }^{1 *}$, Miroslav Šejna ${ }^{2}$, Martinus Th. van Genuchten ${ }^{3,4}$ \\ ${ }^{1}$ Department of Environmental Sciences, University of California, Riverside, CA 92521, USA. \\ ${ }^{2}$ PC-Progress, Ltd., Prague, Czech Republic. \\ ${ }^{3}$ Center for Environmental Studies, CEA, São Paulo State University, UNESP, Rio Claro, SP, Brazil. \\ ${ }^{4}$ Department of Earth Sciences, Utrecht University, Utrecht, Netherlands. \\ *Corresponding author. E-mail: Jiri.Simunek@ucr.edu
}

\begin{abstract}
The capabilities of the HYDRUS-1D and HYDRUS (2D/3D) software packages continuously expanded during the last two decades. Various new capabilities were added recently to both software packages, mostly by developing new standard add-on modules such as HPx, C-Ride, UnsatChem, Wetland, Fumigant, DualPerm, and Slope Stability. The new modules may be used to simulate flow and transport processes in one- and two-dimensional transport domains and are fully supported by the HYDRUS graphical user interface (GUI). Several nonstandard add-on modules, such as Overland, Isotope, and Centrifuge, have also been developed, but are not fully supported by the HYDRUS GUI. The objective of this manuscript is to describe several additional features of the upcoming Version 3 of HYDRUS (2D/3D), which was unveiled at a recent (March 2017) HYDRUS conference and workshop in Prague. The new features include a flexible reservoir boundary condition, expanded root growth features, and new graphical capabilities of the GUI. Mathematical descriptions of the new features are provided, as well as two examples illustrating applications of the reservoir boundary condition.
\end{abstract}

Keywords: HYDRUS; Reservoir boundary condition; Pumping well; Root growth; Graphical user interface.

\section{INTRODUCTION}

The HYDRUS (2D/3D) software package and its various predecessors (e.g., UNSAT, SWMS-2D, CHAIN-2D, and HYDRUS-2D) have a long history that goes back to the early 1970s as documented in detail by Šimůnek et al. (2008, 2016a). The HYDRUS conferences often serve as a forum where new versions of HYDRUS (2D/3D) are unveiled. For example, Version 2 of HYDRUS (2D/3D) and several of its add-on modules (UnsatChem, DualPerm, C-Ride, HP2) were first introduced in 2013 at the Third International Conference on "HYDRUS Software Applications to Subsurface Flow and Contaminant Transport Problems," held in Prague, Czech Republic. Similarly, Version 3 of HYDRUS (2D/3D) was unveiled in 2017 at the Fifth HYDRUS conference in Prague. Similarly, as Version 2, Version 3 is supported by a number of standard and non-standard specialized HYDRUS modules that were summarized by Šimůnek et al. (2016a).

The objective of the present paper is to describe in detail two main computational modules that have been included in Version 3 of HYDRUS (2D/3D): a new "Reservoir" boundary condition" (BC) and a dynamic root system. We provide here not only mathematical descriptions of the new standard computational modules but also two examples illustrating the use of the reservoir BC: i.e., for evaluating the performance of a pumping well as well as of a falling head experiment. Additionally, selected new graphical capabilities of the software package are described.

\section{THE RESERVOIR BOUNDARY CONDITION}

Previous versions of HYDRUS (2D/3D) required that pressure heads at boundaries representing external water bodies be specified as external input. No feedback was possible to relate temporal changes of the water level in these external water bodies in response to interactions with the subsurface, such as infiltration or exfiltration. HYDRUS users typically assumed that the water level in an external water body (e.g., a furrow or borehole) was constant (e.g., Hinnell et al., 2009; Lazarovitch et al. 2009; Warrick et al., 2007), or they needed to prescribe the dynamics of the water level themselves.

Version 3 of the standard two-dimensional computational module of HYDRUS (2D/3D) offers a new system-dependent boundary condition, further referred to as the reservoir boundary condition. This option allows users to consider a reservoir that is external to the HYDRUS transport domain, while water can be added (injected) to or removed (pumped) from the reservoir. Flow into or out of the reservoir through its interface with the subsurface depends on the prevailing conditions in the flow domain (e.g., the position of the groundwater table) and external fluxes. Since mass balances of water and solute in the external reservoir are constantly being updated (based on all incoming and outgoing fluxes), the boundary conditions along the transport domain are dynamically adjusted depending upon the water level in the reservoir.

Reservoir boundary conditions potentially have a large number of applications such as estimating dynamically the water level in wells, in furrows during irrigation, and in wetlands. Another application concerns a relatively new approach to land development known as Low-Impact Development (LID), which is a "green" approach to storm-water management that seeks to mimic the natural hydrology of a site using decentralized microscale control measures (Coffman, 2002). Low-impact development practices range from the use of bioretention cells, infiltration (dry) wells or trenches, stormwater wetlands, wet ponds, level spreaders, permeable pavements, swales, green roofs, vegetated filter and buffer strips, sand filters, smaller culverts, to water harvesting systems (Brunetti et al., 2016, 2017). We provide later two applications where the reservoir $\mathrm{BC}$ is used to evaluate fluxes into or out of wells, as well as to 
a) Well

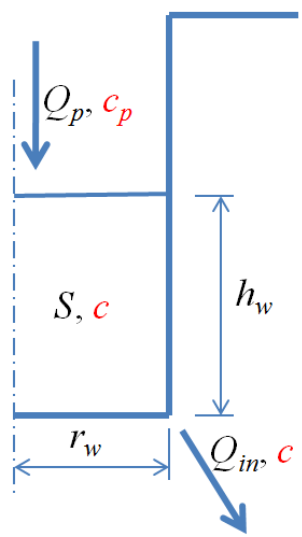

b) Furrow

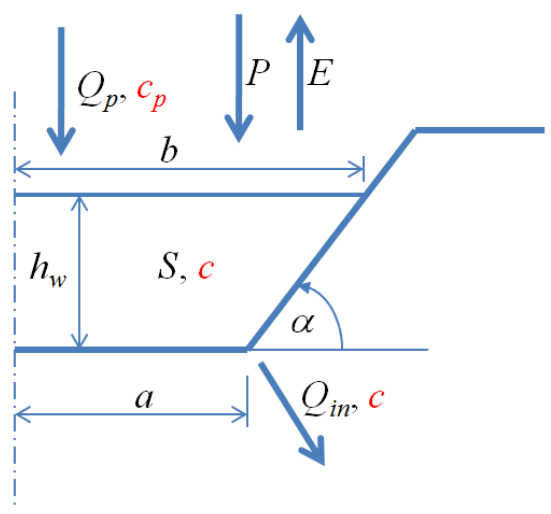

c) Wetland

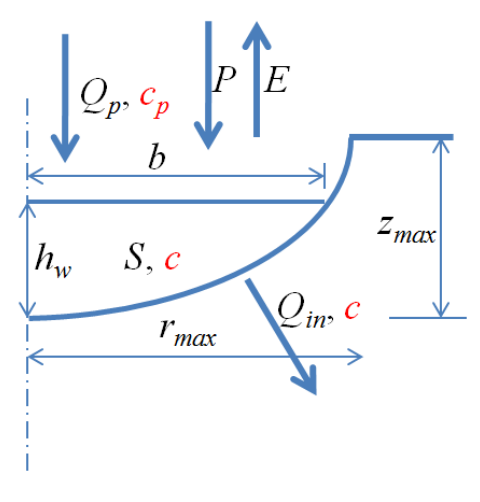

Fig. 1. Three different types of the reservoir boundary condition: a well, a furrow, and a wetland. In the figure $h_{w}$ is the water level in the reservoir [L], $S$ is the volume of water in the reservoir $\left(\left[\mathrm{L}^{2}\right]\right.$ or $\left[\mathrm{L}^{3}\right]$ for two-dimensional and axisymmetric systems, respectively), $Q_{p}$ is the pumping rate (positive for removal of water, negative for adding water) $\left(\left[\mathrm{L}^{2} \mathrm{~T}^{-1}\right]\right.$ or $\left[\mathrm{L}^{3} \mathrm{~T}^{-1}\right]$ for two-dimensional and axisymmetric systems, respectively), $c$ is the solute concentration in reservoir water $\left[\mathrm{ML}^{-3}\right], c_{p}$ is the solute concentration in injected water $\left[\mathrm{ML}^{-3}\right], P$ and $E$ refer to the precipitation and evaporation rates $\left[\mathrm{LT}^{-1}\right], r_{w}$ is the radius of the well [L], $a$ is a half-width of the furrow [L], $\alpha$ is the slope of the furrow side [-], $r_{\max }$ is the maximum width (radius) of the wetland [L], $z_{\max }$ is the maximum depth of the wetland [L], and $b$ represents the width of the water surface $\left([\mathrm{L}]\right.$ or $\left[\mathrm{L}^{2}\right]$ for two-dimensional and axisymmetric systems, respectively).

simulate a falling head experiment.

The reservoir BC is implemented in HYDRUS (2D/3D) for three different geometries (Fig. 1): a well, a furrow, and a wetland. While the furrow $\mathrm{BC}$ is implemented only for twodimensional transport domains, the well and wetland BCs are implemented for both two-dimensional planar and axisymmetric domains.

\section{The Well Reservoir Boundary Condition}

The position of the water level in the well is obtained by solving the following mass balance equation:

$$
\frac{d V_{w}}{d t}=\pi r_{w}^{2} \frac{d h_{w}}{d t}=Q_{i n}(t)-Q_{p}(t)
$$

which in HYDRUS is implemented in terms of the finite difference discretization:

$$
\begin{gathered}
\pi r_{w}^{2} \frac{h_{w}^{j+1}-h_{w}^{j}}{\Delta t}=Q_{i n}-Q_{p} \\
h_{w}^{j+1}=h_{w}^{j}+\frac{\Delta t}{\pi r_{w}^{2}}\left(Q_{i n}-Q_{p}\right)
\end{gathered}
$$

where $V_{w}$ is the volume of water in the well $\left[\mathrm{L}^{3}\right], r_{w}$ is the well radius [L], $h_{w}$ is the water level in the well [L], $Q_{i n}$ is the water flow rate into the well from the soil profile across the well wall (or its screened part) $\left[\mathrm{L}^{3} \mathrm{~T}^{-1}\right], Q_{p}$ is the pumping rate $\left[\mathrm{L}^{3} \mathrm{~T}^{-1}\right], \Delta t$ is the time step [T], and $h_{w}^{j}$ and $h_{w}^{j+1}$ are water levels in the well at the previous and current time levels [L], respectively (Fig. 1a). The fluxes $Q_{i n}$ and $Q_{p}$ can have negative values, in which case they represent outflow from the well (infiltration into the soil profile) and the water flow rate entering the well, respectively.

Equation (1) can be solved providing that the initial position of the water level in the well, $h_{w, i n i t}$, and the pumping rate are known. The parts of the boundary below and above the water level in the well are then assigned internally to be (timevariable) pressure head (Dirichlet) and seepage face boundary conditions, respectively. During execution, HYDRUS calculates which part of the seepage face boundary is active (with a prescribed zero pressure head) and which is inactive (with a prescribed zero flux). HYDRUS also calculates and reports fluxes separately across these two parts of the boundary along a well, and uses these fluxes in Eq. (1). Note that this option can also be used for 2D geometries. The surface area $\pi r_{w}{ }^{2}$ is then replaced with the width, $r_{w}$, of the well bottom.

A similar mass balance equation as for water flow is used also for solute transport:

$$
\begin{aligned}
& \frac{d V_{w} c}{d t}=V_{w} \frac{d c}{d t}+c \frac{d V_{w}}{d t}=Q_{i n} c_{i n}-Q_{p} c_{p} \\
& V_{w} \frac{d c}{d t}=Q_{i n} c_{i n}-Q_{p} c_{p}-c\left(Q_{i n}-Q_{p}\right)
\end{aligned}
$$

where $c$ is the solute concentration in the reservoir $\left[\mathrm{ML}^{-3}\right], c_{i n}$ is solute concentration associated with mass transfer between the soil profile and water reservoir $\left[\mathrm{ML}^{-3}\right]\left(c_{i n}\right.$ is equal to $c$ when water infiltrates into the soil profile and equal to the solute concentration in the soil profile when water exfiltrates into the reservoir), and $c_{p}$ is the solute concentration associated with pumping or injection (equal to $c$ for pumping or to the concentration of water being injected into the reservoir) $\left[\mathrm{ML}^{-3}\right]$. An energy balance equation similarly as Eq. (3) was implemented also to account for heat transport and time-variable temperatures in the reservoir.

\section{The Furrow Reservoir Boundary Condition}

Similarly as for wells, the reservoir BC for furrows within HYDRUS is based on mass balance considerations to determine the position of the water level in the furrow, $h_{w}[\mathrm{~L}]$. The volume of water, $S\left[\mathrm{~L}^{2}\right]$, in the furrow, and its change in time depending 
upon the inflow and outflow rates, are described using the equations (Šimůnek et al., 2016b):

$$
\begin{aligned}
& S=\frac{1}{2} h(a+b)=\frac{1}{2} h_{w}\left(a+a+\frac{h_{w}}{\tan \alpha}\right)=h_{w} a+\frac{h_{w}^{2}}{2 \tan \alpha} \\
& \frac{d S}{d t}=Q_{\text {in }}(t)-Q_{p}(t)+(P-E) b \\
& a \frac{d h_{w}}{d t}+\frac{h_{w}}{\tan \alpha} \frac{d h_{w}}{d t}=\left(a+\frac{h_{w}}{\tan \alpha}\right) \frac{d h_{w}}{d t}= \\
& =Q_{\text {in }}(t)-Q_{p}(t)+(P-E) b
\end{aligned}
$$

or in terms of their finite difference discretization:

$$
\begin{aligned}
& \left(a+\frac{h_{w}^{j}}{\tan \alpha}\right) \frac{h_{w}^{j+1}-h_{w}^{j}}{\Delta t}=Q_{i n}-Q_{p}+(P-E) b \\
& h_{w}^{j+1}=h_{w}^{j}+\frac{\Delta t \tan \alpha}{h_{w}^{j}+a \tan \alpha}\left(Q_{i n}-Q_{p}+P b-E b\right)
\end{aligned}
$$

where $a$ is the half-width of the bottom of the furrow [L], $b$ is the half-width of the water level [L], $h_{w}$ is the water level in the furrow [L], $Q_{i n}$ the water infiltration rate from the furrow to the soil profile across the furrow walls $\left[\mathrm{L}^{2} \mathrm{~T}^{-1}\right], Q_{p}$ is the pumping rate (positive for removal of water, negative for adding water) $\left[\mathrm{L}^{2} \mathrm{~T}^{-1}\right], \Delta t$ is the time step [T], $P$ and $E$ are precipitation and evaporation rates $\left[\mathrm{LT}^{-1}\right]$, respectively, and $h_{w}^{j}$ and $h_{w}^{j+1}$ are water levels in the furrow at the previous and current time levels [L], respectively (Fig. 1b). Similarly, as for the well BC, parts of the boundary below and above the water level in the furrow are then assigned time-variable pressure head (Dirichlet) and seepage face boundary conditions, respectively.

A similar solute mass balance approach as for wells is used also for the furrow BC (Šimůnek et al., 2016b):

$$
\begin{aligned}
& \frac{d(S c)}{d t}=S \frac{d c}{d t}+c \frac{d S}{d t}=Q_{p}(t) c_{p}-Q_{i n}(t) c \\
& S \frac{d c}{d t}=Q_{p}(t) c_{p}-Q_{i n}(t) c-c\left[Q_{p}(t)-Q_{i n}(t)+(P-E) b\right] \\
& S \frac{d c}{d t}=Q_{p}(t)\left(c_{p}-c\right)-c[(P-E) b]
\end{aligned}
$$

where $c_{p}$ is the solute concentration of irrigation water (fertigation) $\left[\mathrm{ML}^{-3}\right.$; or dimensionless $]$, and $c$ is the average solute concentration of the furrow water and hence the concentration of the infiltrating water $\left[\mathrm{ML}^{-3}\right]$. Note that we assume that precipitation and evaporation fluxes are devoid of solutes and that there is instantaneous and complete mixing of solute within the furrow. Precipitation will, therefore, lead to dilution of solute in the furrow water, while evaporation will lead to increasing concentrations. The furrow $\mathrm{BC}$ module requires as input the solute concentration in the irrigation water $\left(c_{p}\right)$ and the timing of fertigation (i.e., the beginning and end time of fertigation). The module then calculates the solute concentration in the furrow water, $c$, which is subsequently used in a Cauchy (concentration flux) boundary condition together with the local infiltration flux calculated with HYDRUS. Similarly, as the standard computational module of HYDRUS, the Reservoir boundary condition cannot be used to account for precipitation/dissolution of mineral phases in the reservoir or its boundaries.

\section{The Wetlands Reservoir Boundary Condition}

Similarly, as for the well and furrow boundary conditions, users can specify a reservoir boundary condition along the boundary of the wetland (Fig. 1c). The bottom coordinates of a wetland are described using the following equations:

$$
\begin{aligned}
& z=z_{\text {max }}\left(\frac{r}{r_{\text {max }}}\right)^{p} \\
& r=r_{\text {max }}\left(\frac{z}{z_{\text {max }}}\right)^{1 / p}
\end{aligned}
$$

where $z_{\max }$ is the depth of a wetland [L], $r_{\max }$ is the radius of a wetland [L], and $p$ is a shape parameter (Fig. 1c). The volume of water in the wetland, $V_{w}\left(\left[\mathrm{~L}^{2}\right]\right.$ or $\left[\mathrm{L}^{3}\right]$ for two- and threedimensional problems, respectively), and the water depth, $h_{w}$ [L], for two-dimensional problems are calculated using:

$$
\begin{aligned}
& d V=r d z=r_{\max }\left(\frac{z}{z_{\text {max }}}\right)^{1 / p} d z \\
& V=\frac{r_{\max }}{\left(z_{\max }\right)^{1 / p}} \int z^{1 / p} d z=\frac{r_{\text {max }}}{\left(z_{\max }\right)^{1 / p}}\left(\frac{p}{1+p}\right) z^{1 / p+1} \\
& h_{w}=\left[\left(\frac{1+p}{p}\right) \frac{\left(z_{\text {max }}\right)^{1 / p}}{r_{\text {max }}} V\right]^{\frac{p}{1+p}}
\end{aligned}
$$

and for axisymmetric problems using:

$$
\begin{aligned}
& d V=\pi r^{2} d z=\pi\left(r_{\max }\right)^{2}\left(\frac{z}{z_{\max }}\right)^{2 / p} d z \\
& V=\pi \frac{\left(r_{\max }\right)^{2}}{\left(z_{\max }\right)^{2 / p}} \int z^{2 / p} d z=\pi\left(\frac{r_{\max }}{z_{\text {max }}^{1 / p}}\right)^{2}\left(\frac{p}{2+p}\right) z^{2 / p+1} \\
& h_{w}=\left[\frac{1}{\pi}\left(\frac{2+p}{p}\right)\left(\frac{z_{\text {max }}^{1 / p}}{r_{\max }}\right)^{2}\right]^{\frac{p}{2+p}}
\end{aligned}
$$

A similar solute mass balance equation as for the well and furrow reservoir BCs is also used for the wetlands reservoir BC.

Before continuing with the two applications, we note that water flow and solute transport can occur in both directions between a reservoir and the transport domain depending upon the prescribed initial and boundary conditions. For example, a reservoir can be initially empty while groundwater table is present in the transport domain. Water will then flow from the transport domain into the reservoir, with HYDRUS dynamically adjusting the boundary conditions at the reservoir walls. The code will assign a time-variable pressure head boundary condition to the reservoir walls that are below the water level in the reservoir, and a seepage face boundary condition to the walls above the water level. At the same time, water may be pumped from or added to the reservoir using other boundary conditions. Alternatively, water could be initially present in or be added to the reservoir, while the transport domain is initially still dry. Water will then flow from the reservoir into the transport domain, in which case the water level in the reservoir and corresponding boundary conditions will be adjusted dynamically based on the fluxes into and out of the reservoir. 
Additionally, the interface between the reservoir and the transport domain is also selected by the software users. For example, in the case of a well reservoir, users can assume that only the bottom or the walls of the well are permeable, or that some part of the well is lined (impermeable to water) or in contact only with certain soil horizons. Since the initial and boundary conditions for the reservoir and the transport domain are specified independently, many different combinations of these various scenarios can hence be accommodated with the new reservoir boundary condition module is HYDRUS. Two examples of these features are given in the next section.

\section{RESERVOIR BOUNDARY CONDITION APPLICATIONS}

We now provide two examples illustrating the use of the well reservoir boundary condition. The first example pertains to a pumping well, with water flowing from the transport domain into the well from which water is being pumped. The water level in the well depends on the balance between water inflow and pumping. The second example considers falling head infiltration, with water flowing from the reservoir into the transport domain, while the water level in the reservoir is correspondingly being adjusted. This example represents a classic falling head infiltration experiment. Additional examples involving furrow reservoir boundary conditions for both water flow and solute transport problems are given by Siyal et al. (2012) and Šimůnek et al. (2016b).

\section{A pumping well}

This example considers conditions typical of a pumping well. The transport domain in the example is assumed to be $5 \mathrm{~m}$ wide and $3 \mathrm{~m}$ deep. The well has a diameter of $0.25 \mathrm{~m}$, is $2 \mathrm{~m}$ deep, and has an initial water level of $0.50 \mathrm{~m}$ above the well bottom. The soil profile is considered to be homogeneous and assumed to consist of loam, with the default van Genuchten (1980) parameters taken from the HYDRUS soil catalog based on textural class-averaged pedotransfer functions derived by Carsel and Parrish (1988). Initial conditions in the profile were assumed to be in static equilibrium with a groundwater table located $50 \mathrm{~cm}$ below the soil surface. Inflow into the well occurred through both the well bottom and its sides. Timevariable pressure head and seepage face boundary conditions were applied at the well boundary below and above the water level in the well, respectively. A constant pressure head boundary condition, corresponding to the initial pressure head conditions was specified along the right side of the domain, while no flow boundary conditions were imposed at all other boundaries. The pumping rate from the well was set equal to $0.03 \mathrm{~m}^{3} / \mathrm{h}$.

The transport domain was discretized into an unstructured triangular finite element mesh, with a targeted element size of $0.075 \mathrm{~m}$. The size of finite elements was adjusted to $0.03 \mathrm{~m}$ at the well bottom and $0.3 \mathrm{~m}$ at the right side of the domain. The transport domain and its discretization are shown in Figure 2.

Figure 3 shows the water level and water volume in the well, as well cumulative water fluxes, as a function of time. Initially, the pumping rate was slightly smaller than the inflow rate of water from the soil into the well through the well walls below (Exfiltration) and above (Seepage) the water level in the well. As a result, the water level in the well and the well water volume slightly increase. However, the inflow of water into the well after about 10 hours was about equal to, and then became smaller than, the pumping rate, leading to a gradual but slow decrease in the water level in the well. Figure 4 shows calcu-

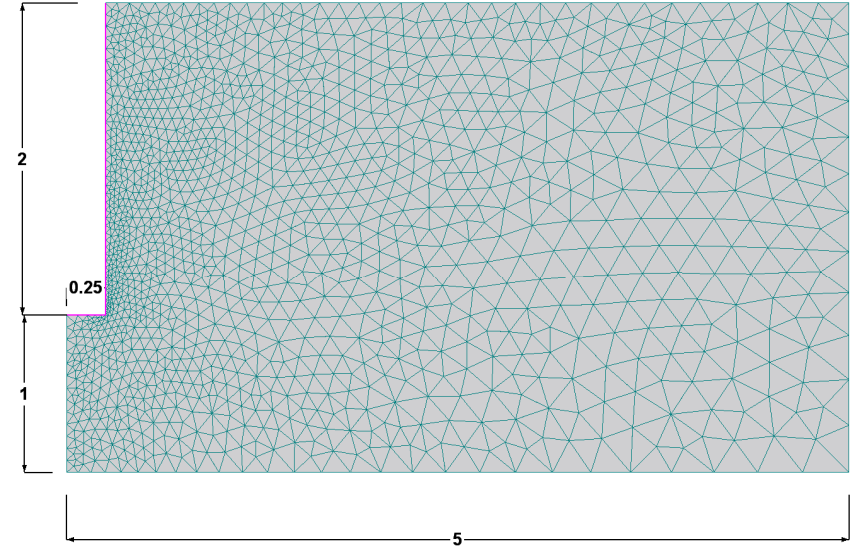

Fig. 2. The transport domain and its discretization for the pumping well example. Values in the figure are in meters.

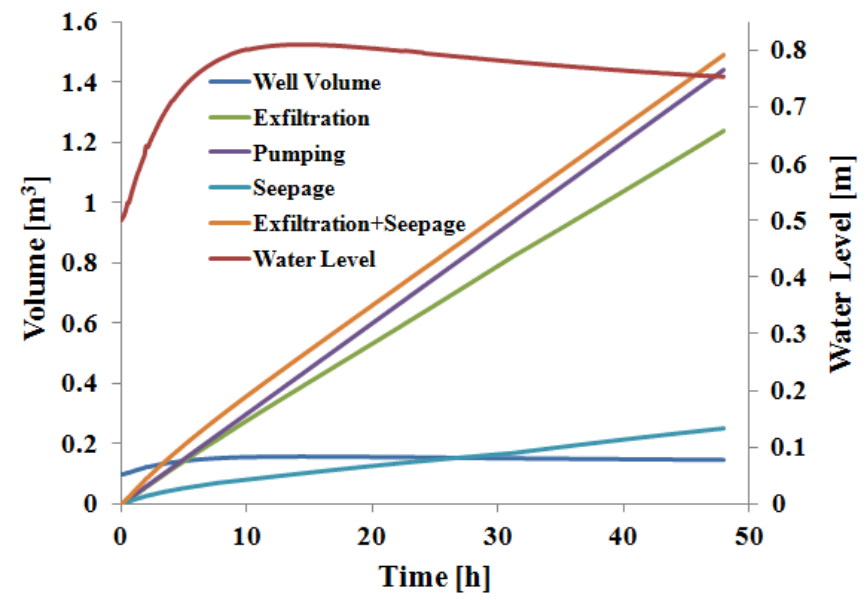

Fig. 3. Calculated water levels and water volumes in the well, and cumulative water fluxes as a function of time for the pumping well example. Note that the terms "Exfiltration" and "Seepage" represent cumulative flow from the transport domain into the well, while "Pumping" refers to the removal of water from the well.

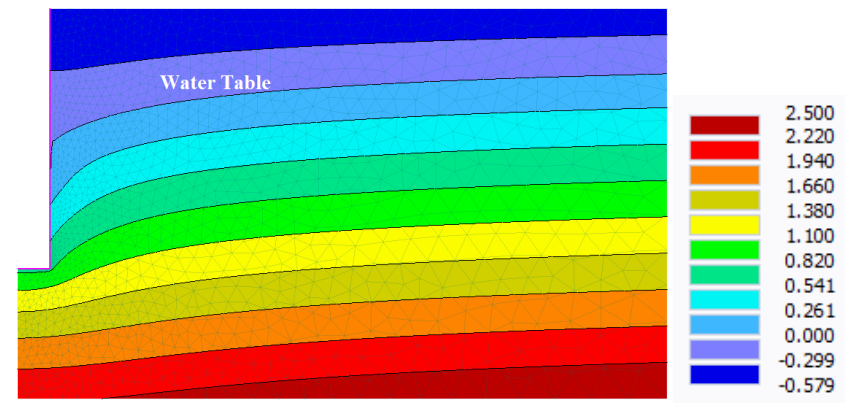

Fig. 4. Calculated pressure head $(\mathrm{m})$ profile and position of the water table after 48 hours of pumping for the pumping well example.

lated pressure head profiles and the position of the water table after 48 hours of pumping.

While relatively simple, the example demonstrates the use of the new reservoir boundary condition. The problem in actuality can be made much more complex, for example by assuming a 
heterogeneous soil profile, making the pumping rate time variable, assuming different parts of the well to be screened, and including contaminant transport among essentially all other features available in the standard HYDRUS (2D/3D) software package.

\section{Falling head infiltration}

In this example, the well reservoir boundary condition is used to simulate a falling head experiment when the water reservoir is placed on top of the soil. The transport domain in this example was $1.25 \mathrm{~m}$ wide and $1.30 \mathrm{~m}$ deep, and discretized into a structured finite element mesh consisting of 380 nodes and 684 elements. The soil profile was again considered to be homogeneous and to consist of loam, with the default van Genuchten (1980) parameters taken from the HYDRUS soil catalog. The radius of the reservoir placed on top of the soil surface was $0.20 \mathrm{~m}$, and the initial water level in the reservoir $0.15 \mathrm{~m}$ above the soil surface.

Figure 5 shows that the water level and the water volume in the reservoir decreased as a result of water infiltrating into the soil profile. At the end of the experiment, all water initially in the reservoir infiltrated into the soil profile. Note that in Figure 5 the "Volume" at time zero is equal to cumulative "Infiltration" at the end of the experiment. Figure 6 shows the calculated pressure head profiles at $0.2 \mathrm{~d}$ when water is still infiltrating into the profile, and at $0.5 \mathrm{~d}$ during redistribution when the reservoir is empty. The plots hence represent situations during and after the falling head infiltration experiment.

\section{ROOT GROWTH}

Previous Version 2 of HYDRUS(2D/3D) included a relatively comprehensive macroscopic root water and solute uptake model (Šimůnek and Hopmans, 2009) to account for the effects of both water and salinity stress on root water uptake, while additionally accounting for possible active and passive root contaminant or nutrient uptake. Root water and solute uptake both could furthermore be treated as being either noncompensated or compensated, while users could select the degree of compensation (Šimůnek and Hopmans, 2009).

HYDRUS-1D additionally allowed users to externally prescribe a time-variable rooting depth, either using the logistic growth function or a tabulated form. This feature was thus far not available in HYDRUS (2D/3D), which has been noted by

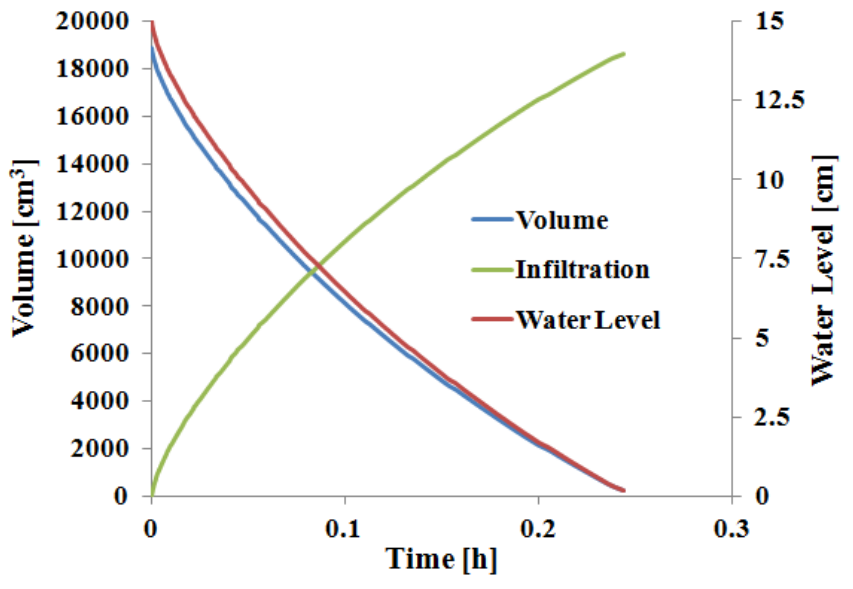

Fig. 5. Calculated water levels and water volumes in the reservoir on top of the soil, and cumulative infiltration volumes into the soil, as a function of time for the falling head experiment.

several HYDRUS users (e.g., Karandish and Šimůnek, 2016; Ramos et al., 2012; Roberts et al., 2009; among others). The spatial distribution of roots in the root zone was assumed to remain constant during the simulations, and only the intensity of potential uptake (as a result of time-variable potential transpiration rates) could be specified as input. The HYDRUS models also did not allow the spatial extent of the rooting zone to change actively as a result of certain environmental stresses (e.g., Hartman et al., 2018).

To overcome these deficiencies, several studies either further modified the HYDRUS models (or their predecessors such as CHAIN-2D or SWMS-3D), or coupled the models with existing crop growth or root growth models. For example, Javaux et al. (2008, 2013) developed R-SWMS, a threedimensional root growth model that couples the model of Somma et al. (1998) (based on SWMS-3D) with the root architecture model of Doussan et al. (1998). Zhou et al. (2012) coupled HYDRUS-1D with the WOFOST crop growth model (Boogaard et al., 1998), and used the resulting code to simulate the growth and yield of irrigated wheat and maize ( $\mathrm{Li}$ et al., 2012, 2014). Han et al. (2015) similarly coupled HYDRUS-1D with a simplified crop growth version used in SWAT, based on the EPIC root growth model (Williams et al., 1989). They used the coupled model to simulate the contribution and impact of groundwater on cotton growth and root zone water balance.
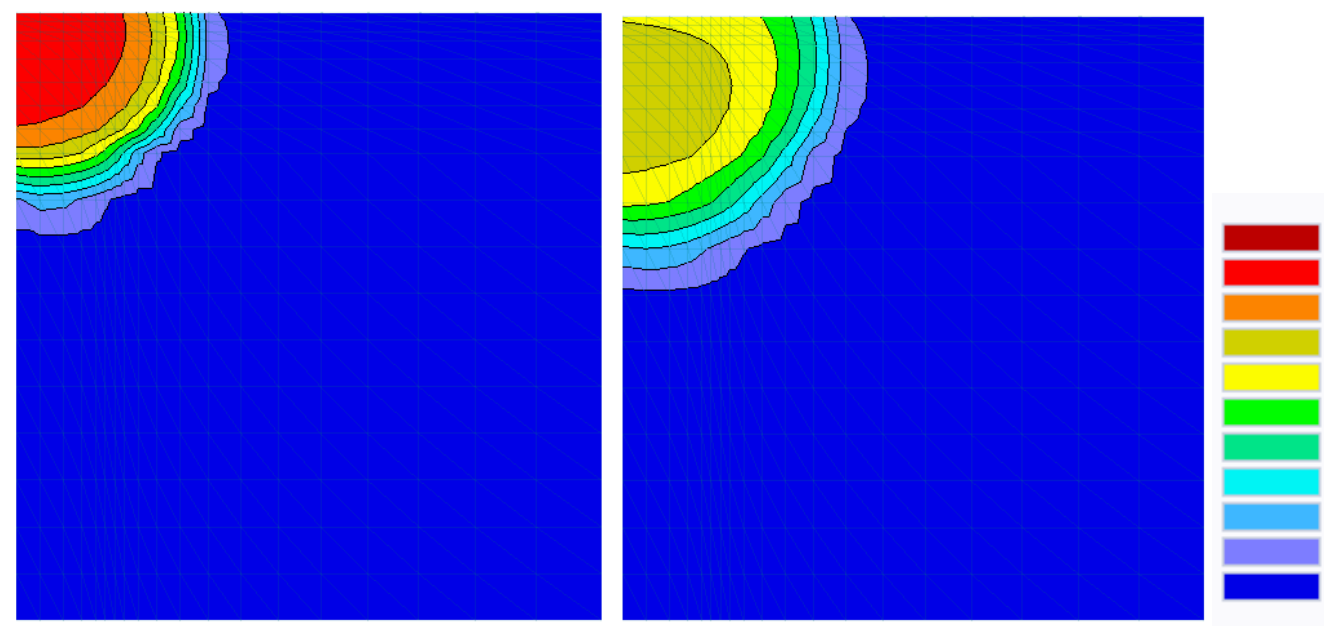

Fig. 6. Calculated pressure head $(\mathrm{cm})$ profiles at 0.2 (left) and $0.5 \mathrm{~d}$ (right) for the falling head experiment. 
Wang et al. $(2014,2015)$ further coupled EPIC with CHAIN-2D and HYDRUS-1D to assess the effects of furrow and sprinkler irrigation, respectively, on crop growth. Finally, Hartmann et al. (2018) implemented into both HYDRUS-1D and HYDRUS (2/3D) a root growth model developed by Jones et al. (1991). Their coupled model assumes that various environmental growth stress factors can influence root development under suboptimal conditions. Of the different software, only the models of Hartmann et al. (2018) are directly available from the HYDRUS website as a non-standard HYDRUS module (i.e., not fully supported by the HYDRUS GUI).

To extend the capabilities of the standard module of HYDRUS (2D/3D), a simple root growth model with similar capabilities as those in HYDRUS-1D was implemented into Version 3 . The rooting depth, $L_{R}$, can now be either constant (the standard approach) or variable during the simulations. For annual vegetation, a growth model is required to simulate changes in rooting depth with time. Time-variable rooting depth values can be provided either using a table on input, or calculated with the program assuming that the actual rooting depth is the product of the maximum rooting depth, $L_{m}[\mathrm{~L}]$, and a root growth coefficient, $f_{r}(t)[-]$, given by:

$$
L_{R}(t)=L_{m} f_{r}(t)
$$

For the root growth coefficient, $f_{r}(t)$, we use the classical Verhulst-Pearl logistic growth function

$$
f_{r}(t)=\frac{L_{0}}{L_{0}+\left(L_{m}-L_{0}\right) e^{-r t}}
$$

where $L_{0}$ is the initial value of the rooting depth at the beginning of the growing season [L], and $r$ the growth rate $\left[\mathrm{T}^{-1}\right]$. The growth rate can be calculated either from the assumption that $50 \%$ of the rooting depth will be reached after $50 \%$ of the growing season has elapsed or from given data of the rooting depth at a specified time. The same approach is also used for the horizontal extent of the rooting zone, except that the maximum extent of the rooting zone in the horizontal direction is used instead of the maximum rooting depth.

When a variable rooting depth is considered, the spatial distribution of roots must be described using either the Vrugt
(Vrugt et al., 2001a, 2001b) or Hoffman and van Genuchten (Hoffman and van Genuchten, 1983) functions. The Vrugt twodimensional root distribution function is implemented in HYDRUS as follows (Vrugt et al., 2001a, 2001b):

$$
b(x, z)=\left(1-\frac{z}{Z_{m}}\right)\left(1-\frac{x}{X_{m}}\right) e^{-\left(\frac{p_{z}}{Z_{m}}\left|z^{*}-z\right|+\frac{p_{r}}{X_{m}}\left|x^{*}-x\right|\right)}
$$

where $X_{m}$ and $Z_{m}$ are the maximum rooting lengths in the $x$ - and $z$ - directions [L], respectively; $x$ and $z$ are distances from the origin of the plant (or tree) in the $x$ - and $z$-directions [L], respectively; $p_{x}[-], p_{z}[-], x^{*}[\mathrm{~L}]$, and $z^{*}[\mathrm{~L}]$ are empirical parameters (Vrugt et al., 2001b), and $b(x, z)$ denotes the twodimensional spatial distribution of the potential root water uptake rate [-]. The parameters $x^{*}$ and $z^{*}$ indicate the location in the profile having the maximum rooting density, while $p_{x}$ and $p_{z}$ are assumed to be zero for $x>x^{*}$ and $z>z^{*}$, respectively. We refer to Vrugt et al. (2001a, 2001b) for different configurations of the normalized spatial distribution of the potential root water uptake rate.

Alternatively, one can use the following function (Hoffman and van Genuchten, 1983):

$$
b(z)=\left\{\begin{array}{cl}
\frac{1.667}{Z_{m}} & z>L-0.2 Z_{m} \\
\frac{2.0833}{Z_{m}}\left(1-\frac{L-z}{Z_{m}}\right) & z \in\left(L-Z_{m} ; L-0.2 Z_{m}\right) \\
0 & z<L-Z_{m}
\end{array}\right.
$$

where $L$ is the $x$-coordinate of the soil surface [L] and $Z_{m}$ is the rooting depth [L].

Figure 7 shows an example of the two-dimensional spatial distribution of root water uptake at 10, 20,30, and $40 \mathrm{~d}$ in a transport domain that is $100 \mathrm{~cm}$ wide and $150 \mathrm{~cm}$ deep. The plots are for the following root growth parameters: $L_{0 x}=L_{0 z}=5$ $\mathrm{cm}$ at $t=5 \mathrm{~d}, Z_{m}=L_{m z}=100 \mathrm{~cm}$ at $t=45 \mathrm{~d}, X_{m}=L_{m x}=75 \mathrm{~cm}$, $x^{*}=0, z^{*}=20 \mathrm{~cm}, p_{x}=p_{z}=1$. The root growth rate $r$ for these variables was equal to $-0.0309 \mathrm{~d}^{-1}$.
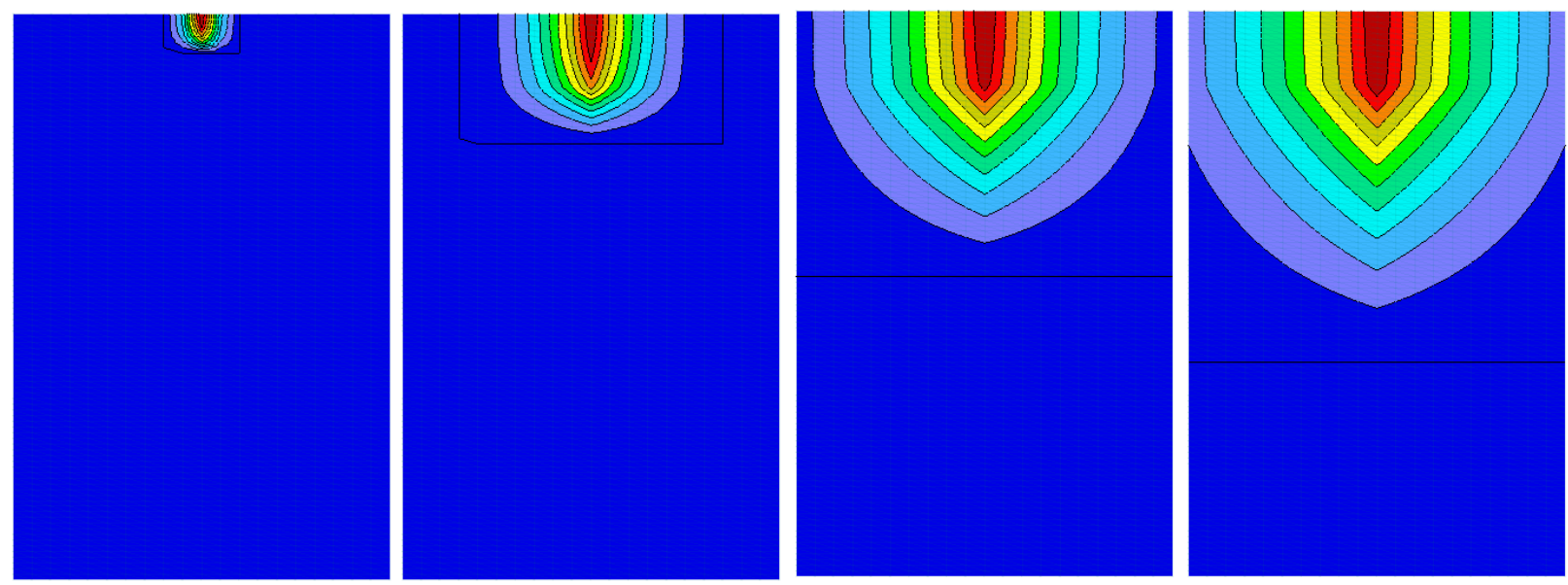

Fig. 7. Dynamic two-dimensional spatial distribution of root water uptake at $10,20,30$, and $40 \mathrm{~d}$ for root growth parameters given in the text. The transport domain is $100 \mathrm{~cm}$ wide and $150 \mathrm{~cm}$ deep. The scale varies from zero (blue) to one (red) and is dimensionless. 


\section{THE HYDRUS (2D/3D) GRAPHICAL USER INTERFACE}

The popularity of the HYDRUS software packages is in large part due to its inclusion of a large number of subsurface and near-surface water flow and solute transport processes (Šimůnek et al., 2016a). However, equally important has been the development of advanced graphical user interfaces (GUIs). The GUI of Version 3 of HYDRUS (2D/3D) now includes a significant number of major new features, as well as a large number of smaller corrections and improvements. Although the external look has been preserved and is similar to Version 2, Version 3 internally uses the latest software development tools and libraries, which is critical to ensure compatibility with new Windows operating systems and development of more efficient software in the future. This section provides a brief overview of the most important improvements and extensions.

One important objective with new version was to increase the performance and capacity of the GUI. The limit of Version 2 of HYDRUS (about 1 million finite elements) was extended by almost an order to 10 million finite elements. The extension was achieved by overall optimization of the code and developing a 64-bit version of HYDRUS, which can now use all physical memory available on modern PCs. This feature permitted a considerable increase in the size of HYDRUS simulations, with the main limiting factor now being the speed of the calculation module(s).

We further replaced many old HYDRUS (2D/3D) software components for charts and tables in Version 3 by new components, which also included fixing some known errors. Now all dialogs containing charts or tables are resizable, thus making entering and viewing data more comfortable. The GUI also supports the Unicode and can now correctly display special characters such as Greek symbols. Although manipulating graphical objects in HYDRUS, in general, was relatively easy thanks to drag-and-drop features, some operations (such as rotations) had to be defined numerically in a dialog box. Version 3 offers a new graphical tool called "Manipulator" for more user-friendly transformations of selected objects in two or three dimensions.

We also improved several features related to Mesh-sections, 3D mesh clipping and slicing. The optimization of a GUI for work with relatively large FE meshes required certain changes in using mesh-sections. While mesh-sections are still fully supported, the program by default does not generate as many mesh-sections as in Version 2. However, we created a new graphical tool called "Clipper" that can now be used to cut or slice a 3D mesh. Figures 8 and 9 show examples of these two applications. Another useful function related to mesh-sections is the possibility to select mesh nodes or elements by selecting geometric objects in a data-explorer tree.

The graphical display of velocity vectors for millions of mesh nodes is not only slow but usually also too complex for viewing. We improved the new GUI to allow displays of velocity vectors either at mesh nodes or raster points, while the raster parameters (such as the density of points) are fully adjustable. Figure 10 shows an example.

Previous Version 2 of HYDRUS (2D/3D) allowed one to show flowing particles, but only in two dimensions. Flowing particles are hypothetical objects that can be defined at any location of the transport domain by users, with the program then calculating trajectories and positions of these particles with time considering unretarded convective transport. The "flowing particles" feature is now available for both $2 \mathrm{D}$ and $3 \mathrm{D}$ projects.

Another new feature of Version 3 is the calculation and display of streamlines for a given steady-state flow velocity field.
Streamlines are one of the most commonly used graphical representations of CFD (computational flow dynamics) results in that they can display very clearly the flow direction, such as shown in Figure 11. The software now also has an option to run flow animations, i.e., the movement of particles along streamlines (Fig. 12). Users can save this animation as a video file and use in presentations of HYDRUS results.

The ability of charts displaying the distribution of various quantities along boundary-lines and cross-section lines has also been extended in Version 3. The GUI now allows the display of results at multiple time-layers simultaneously in one chart. This feature allows one to compare very easily values of a given quantity at different times. Note that cross-section lines and charts now can be also applied to mesh slices created by the Clipper tool as described earlier and shown in Figure 8.

We further improved the 3D graphics of Version 3 of HYDRUS, including allowing the rendering to be smoother and faster. A transparent mode (object translucency) is now available also for the graphical display of results. An example of this is shown in Figure 13. We included at the same time new options for automatic numbering of isolines and displaying positions of minimum/maximum values of a current quantity.

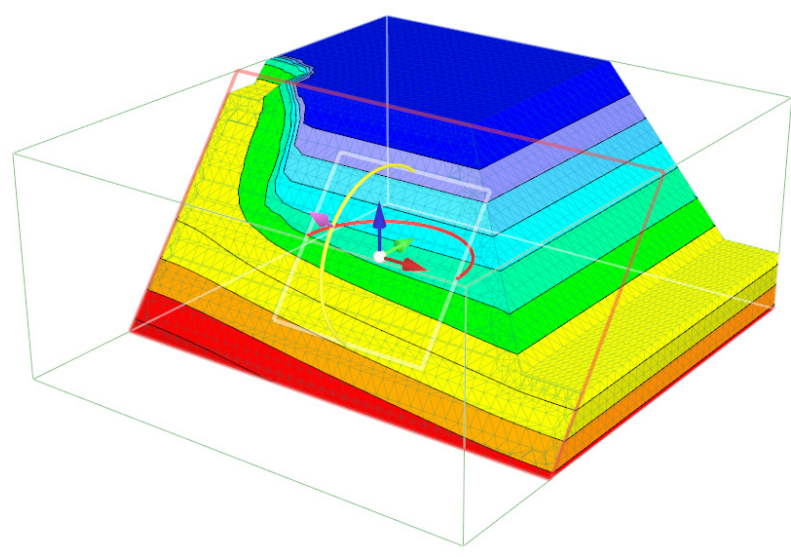

Fig. 8. Example showing 3D Clipping. When working with 3D models, the visible mesh (or geometric objects) can be clipped to view values inside the domain. The clipper is controlled by a graphical tool (a manipulator).

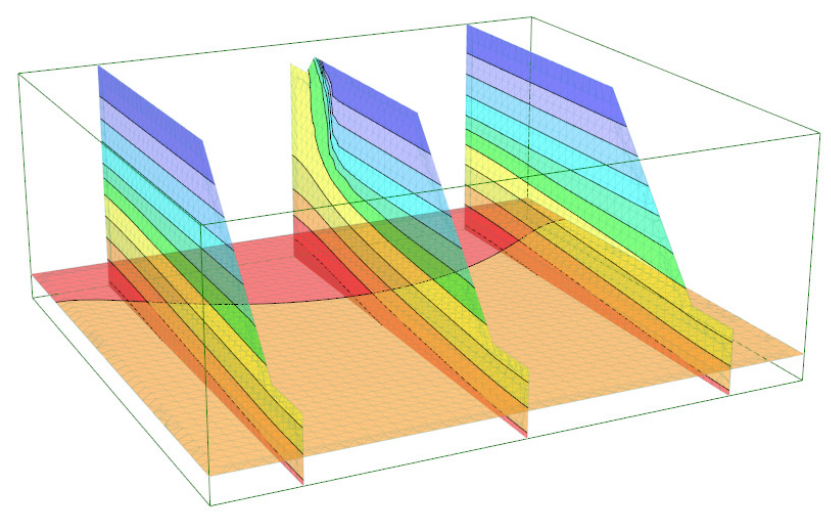

Fig. 9. Example showing 3D Slicing. The slicer is another tool for better visualization of 3D objects. The number of slices, their position and rotation can be set either in a dialog or graphically. 

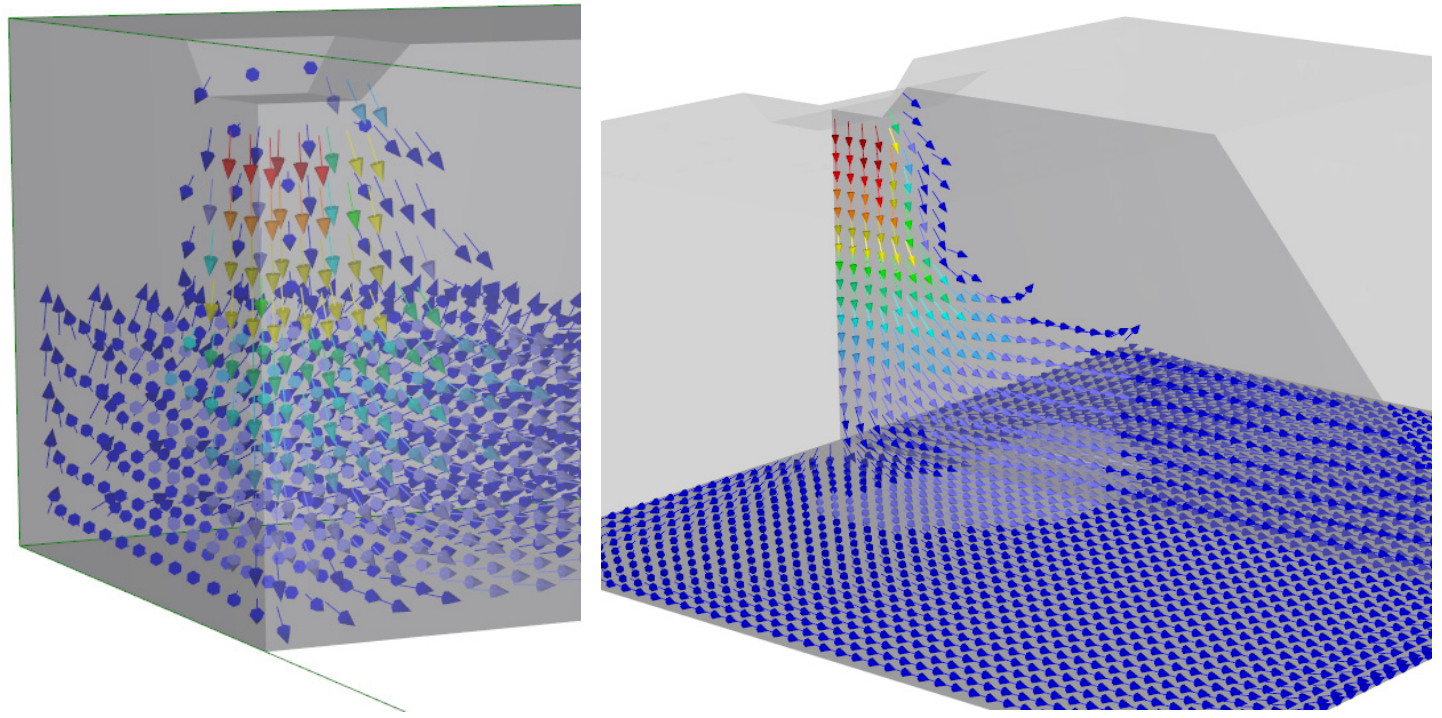

Fig. 10. Rasters for Vector Fields. Vector fields can be displayed in mesh-independent rasters, i.e., regular 2D/3D grids with an arbitrary density of points. Rasters can also be used with the Clipper and Slicer.

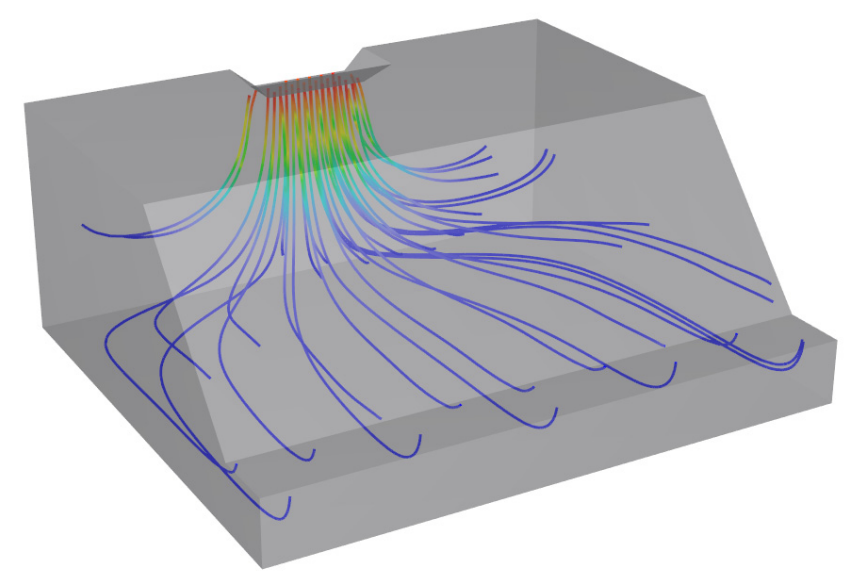

Fig. 11. Example showing 3D Streamlines. Streamlines can be calculated for a given time layer (i.e., steady-state flow) from a set of seed points. Seed point sources of several types can be set graphically.

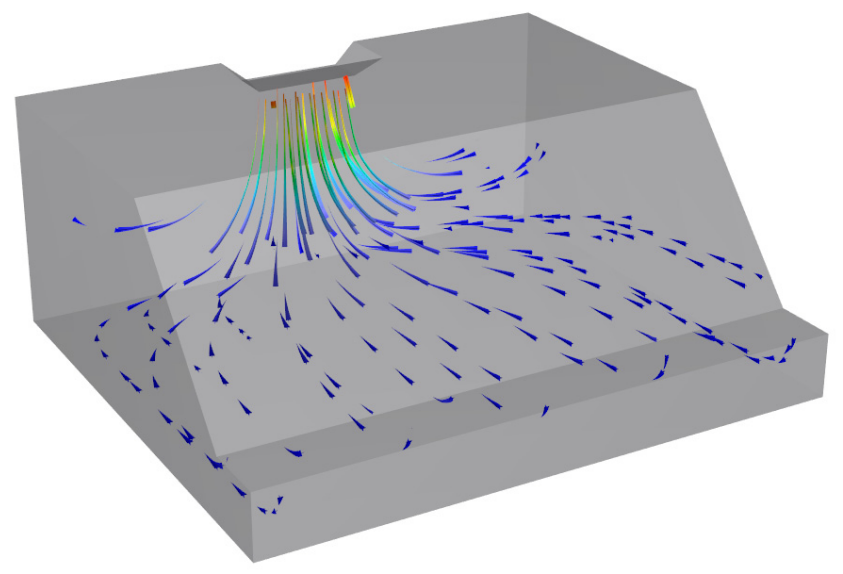

Fig. 12. Example of Particle Animation. The movement of particles can be animated as flowing-lines or flowing-particles.

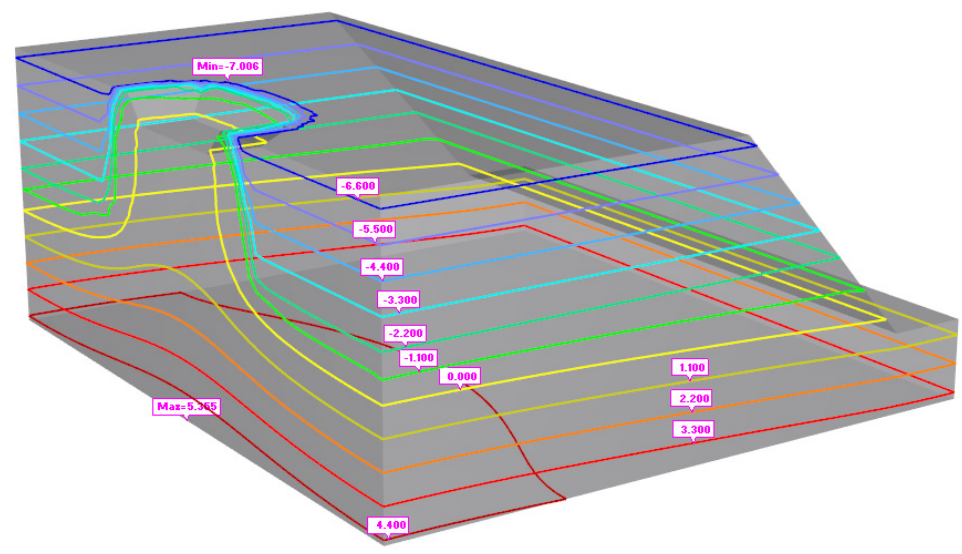

Fig. 13. Example of the Transparent mode of the HYDRUS GUI. The Transparent mode is available for all types of graphical displays of scalar and vector fields. Isolines are automatically numbered, and $\mathrm{min} / \mathrm{max}$ values of a particular variable in the transport domain are automatically identified. 


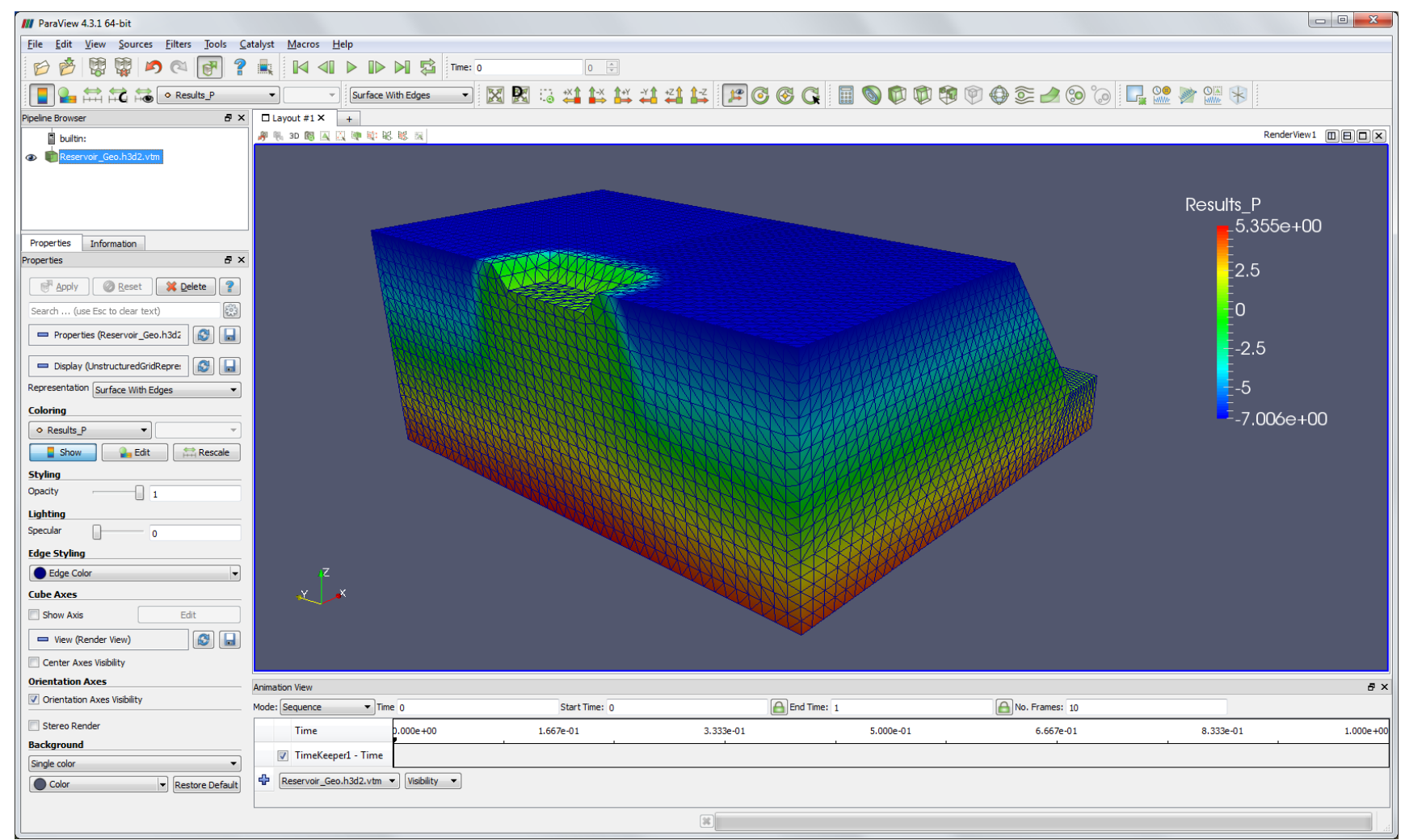

Fig. 14. Example showing Export to ParaView. ParaView is an open-source, multi-platform data analysis and visualization application. New visualization options include custom post-processing based on scripting or plugin modules. Details are at www.paraview.org.

Although we believe that HYDRUS post-processing has all of the most important features needed for project execution, some users may require additional functions specific to their own needs. The new version of HYDRUS offers a robust solution by exporting all results to VTK files. VTK is a well-known open source library intended for the visualization of scientific data. Exported HYDRUS results can then be opened in ParaView, such as illustrated in Figure 14, which is a free program based on VTK. Since both software products (VTK and ParaView) are open source, users have full control over the exported data and can implement any special post-processing as judged optimal for their application.

\section{CONCLUSIONS}

While HYDRUS (2D/3D) and its various predecessors, such as UNSAT, SWMS-2D, and CHAIN-2D, have been available to the public for over 20 years, the software package is under constant development, with new features being continuously added. This manuscript describes two main new capabilities (a general reservoir boundary condition and a dynamic root growth module) that recently were incorporated in the standard computational module. The capability to simulate the root growth in HYDRUS (2D/3D) has regularly been requested for quite some time by many users, and thus may well become a popular new feature. Similarly, the "Reservoir" boundary condition offers new capabilities for application to a large number of field problems, such as well pumping or the drying of wells, furrow irrigation design and analysis, falling head infiltration experiments, and a range of new approaches to land development known as Low-Impact Development (LID). We also summarized in this paper several new capabilities of the HY-
DRUS (2D/3D) graphical user interface. Continuous updating of the HYDRUS GUI not only guarantees that the software will be fully operational with new Window operating systems, but also will offer more convenient tools, options, and ease of use to its users.

\section{REFERENCES}

Boogaard, H., van Diepen, C., Rotter, R., Cabrera, J., van Laar, H., 1998. WOFOST 7.1: User's guide for the WOFOST 7.1 crop growth simulation model and WOFOST control center 1.5. Tech. Rep. DLO Winand Staring Ctr., Wageningen, the Netherlands.

Brunetti, G., Šimůnek, J., Piro, P., 2016. A comprehensive analysis of the variably-saturated hydraulic behavior of a green roof in Mediterranean climate. Vadose Zone Journal, 15, 9, 15 p. DOI: 10.2136/vzj2016.04.0032.

Brunetti, G., Šimůnek, J., Turco, M., Piro, P., 2017. On the use of surrogate-based modeling for the numerical analysis of Low Impact Development techniques. Journal of Hydrology, 548, 263-277. DOI: 10.1016/j.jhydrol.2017.03.013.

Carsel, R.F., Parrish, R.S., 1988. Developing joint probability distributions of soil water retention characteristics. Water Resources Research, 24, 755-769.

Coffman, L.S., 2002. Low-impact development: An alternative stormwater management technology. In: France, R.L. (Ed.): Handbook of Water Sensitive Planning and Design. Lewis Publ., Boca Raton, FL, pp. 97-123.

Doussan, C., Pages, L., Vercambre, G., 1998. Modelling of the hydraulic architecture of root systems: An integrated approach to water absorption - Model description. Ann. Bot., $81,213-223$. 
Han, M., Zhao, C., Šimůnek, J., Feng, G., 2015. Evaluating the impact of groundwater on cotton growth and root zone water balance using Hydrus-1D coupled with a crop growth model. Agricultural Water Management, 160, 64-75. DOI: 10.1016/j.agwat.2015.06.028.

Hartmann, A., Šimůnek, J., Aidoo, M.K., Seidel, S.J., Lazarovitch, N., 2018. Modeling root growth as a function of different environmental stresses using HYDRUS. Vadose Zone Journal, 16 p. DOI: 10.2136/vzj2017.02.0040.

Hinnell, A.C., Lazarovitch, N., Warrick, A.W., 2009. Explicit infiltration function for boreholes under constant head conditions. Water Resour. Res., 45, W10429. DOI: 10.1029/2008WR007685.

Hoffman, G.J., van Genuchten, M.T., 1983. Soil properties and efficient water use: Water management for salinity control. In: Taylor, H.M., Jordan, W.R., Sinclair, T.R. (Eds.): Limitations and Efficient Water Use in Crop Production. Am. Soc. of Agron., Madison, WI, pp. 73-85.

Javaux, M., Schröder, T., Vanderborght, J., Vereecken, H., 2008. Use of a three-dimensional detailed modeling approach for predicting root water uptake. Vadose Zone Journal, 7, 1079-1088. DOI: 10.2136/vzj2007.0115.

Javaux, M., Couvreur, V., Vanderborght, J., Vereecken, H., 2013. Root water uptake: From three-dimensional biophysical processes to macroscopic modeling approaches. Vadose Zone Journal, 12, 4, 16 p. DOI: 10.2136/vzj2013.02.0042.

Jones, C., Bland, W., Ritchie, J., Williams, J.R., 1991. Simulation of root growth. Modeling Plant and Soil Systems-Agronomy Monograph, Segoe Rd., Madison, WI 53711, USA, ASA-CSSA-SSSA, 31, pp. 91-123.

Karandish, F., Šimůnek, J., 2016. A comparison of numerical and machine-learning modeling of soil water content with limited input data. Journal of Hydrology, 543, 892-909. DOI: 10.1016/j.jhydrol. 2016.11.007.

Lazarovitch, N., Warrick, A.W., Furman, A., Zerihun, D., 2009. Subsurface water distribution from furrows described by moment analyses. J. Irrig. Drain. Eng., 135, 1, 7-12.

Li, Y., Kinzelbach, W., Zhou, J., Cheng, G.D., Li, X., 2012. Modelling irrigated maize with a combination of coupledmodel simulation and uncertainty analysis, in the northwest of China. Hydrol. Earth Syst. Sci., 16, 1465-1480.

Li, Y., Zou, Q., Zhou, J., Zhang, G., Chen, C., Wang, J., 2014. Assimilating remote sensing information into a coupled hydrology-crop growth model to estimate regional maize yield in arid regions. Ecological Modelling, 291, 15-27.

Ramos, T.B., Šimůnek, J., Gonçalves, M.C., Martins, J.C., Prazeres, A., Pereira, L.S., 2012. Two-dimensional modeling of water and nitrogen fate from sweet sorghum irrigated with fresh and blended saline waters. Agricultural Water Management, 111, 87-104. DOI: 10.1016/j.agwat.2012.05.007.

Roberts, T.L., Lazarovitch, N., Warrick, A.W, Thompson, T.L., 2009. Modeling salt accumulation with subsurface drip irrigation using HYDRUS-2D. Soil Sci. Soc. Am. J., 73, 1, 233-240. DOI: 10.2136/sssaj2008.0033.
Siyal, A.A., Bristow, K.L., Šimůnek, J., 2012. Minimizing nitrogen leaching from furrow irrigation through novel fertilizer placement and soil management strategies. Agricultural Water Management, 115, 242-251. DOI: 10.1016/j.jconhyd.2012.03.008.

Šimůnek, J., Hopmans, J.W., 2009. Modeling compensated root water and nutrient uptake. Ecological Modeling, 220, 4, 505-521. DOI: 10.1016/j.ecolmodel.2008.11.004.

Šimůnek, J., van Genuchten, M.T., Šejna, M., 2008. Development and applications of the HYDRUS and STANMOD software packages and related codes. Vadose Zone Journal, 7, 2, 587-600. DOI: 10.2136/VZJ2007.0077.

Šimůnek, J., van Genuchten, M. T., Šejna, M., 2016a. Recent developments and applications of the HYDRUS computer software packages. Vadose Zone Journal, 15, 7, 25 p. DOI: 10.2136/vzj2016.04.0033.

Šimůnek, J., Bristow, K.L., Helalia, S.A., Siyal, A.A., 2016 b. The effect of different fertigation strategies and furrow surface treatments on plant water and nitrogen use. Irrigation Science, 34, 1, 53-69. DOI: 10.1007/s00271-015-0487-z.

Somma, F., Hopmans, J.W., Clausnitzer, V., 1998. Transient three-dimensional modeling of soil water and solute transport with simultaneous root growth, root water and nutrient uptake. Plant Soil, 202, 281-293.

van Genuchten, M.T., 1980. A closed-form equation for predicting the hydraulic conductivity of unsaturated soils. Soil Sci. Soc. Am. J., 44, 987-996.

Vrugt, J.A., Hopmans, J.W., Šimůnek, J., 2001a. Calibration of a two-dimensional root water uptake model. Soil Sci. Soc. Amer. J., 65, 4, 1027-1037.

Vrugt, J.A., van Wijk, M.T., Hopmans, J.W., Šimůnek, J., 2001 b. One-, two-, and three-dimensional root water uptake functions for transient modeling. Water Resources Research, $37,10,2457-2470$.

Wang, J., Huang, G., Zhan, H., Mohanty, B.P., Zheng, J., Huang, Q., Xu, X., 2014. Evaluation of soil water dynamics and crop yield under furrow irrigation with a twodimensional flow and crop growth coupled model. Agricultural Water Management, 141, 10-22.

Wang, X., Huang, G., Yang, J., Huang, Q., Liu, H., Yu, L., 2015. An assessment of irrigation and fertilization practices: Sprinkler irrigation of winter wheat in the North China Plain. Agricultural Water Management, 159, 197-208.

Warrick, A.W., Lazarovitch, N., Furman, A., Zerihun, D., 2007. Explicit infiltration function for furrows. J. Irrig. Drain. Eng., 133, 4, 307-313.

Williams, J.R., Jones, C.A., Kiniry, J.R., Spanel, D.A., 1989. The EPIC crop growth model. Trans. ASAE, 32, 2, 497511.

Zhou, J., Cheng, G., Li, X., Hu, B.X., Wang, G., 2012. Numerical modeling of wheat irrigation using coupled HYDRUS and WOFOST models. Soil Sci. Soc. Amer. J., 76, 2, 648662. DOI: $10.2136 /$ sssaj2010.0467.

Received 14 August 2017 Accepted 4 October 2017 